\title{
Glial microtumor with 17-year of postoperative follow up
}

\author{
José Alberto Gonçalves da Silva', Maria Desterro Leiros da Costa², \\ Luiz Ricardo Santiago Melo', Antônio Fernandes de Araújo', \\ Jurandy Lins de Araújo3 ${ }^{3}$, Vamberto Augusto Costa Filho ${ }^{4}$, \\ Adailton Arcanjo dos Santos Junior ${ }^{5}$
}

Reports about biological behavior of gliomas most commonly describe the latest stages of their natural course $\mathrm{e}^{1-3}$. However, studies about the earliest stages of human astrocytomas are rare. Nishio et al. ${ }^{1}$ stated that $1 \%$ to $2 \%$ of necropsies may contain some type of undiagnosed glioma. Identification of microscopic foci of astrocytic cells at the primary phase of a glioma is extremely rare. Tamura et al. ${ }^{3}$ reported that whereas the majority of small gliomas tends to be benign and malignant tumors invade neighboring tissues early on their development. Rubinstein ${ }^{4}$ reported that the most primitive cells of the reticular system found in the meninges and perivascular sheaths of cerebral vessels, along with the microglia, originate the reticular cell sarcoma (microglioma group). However, Amacher et al. ${ }^{5}$ believe that the congenital cerebellar medulloblastomas which the remnants of primitive cells located in the fetal external granular layer. These authors observed the presence of microscopic medulloblastoma on necropsy exam in a neonate with 8 hours of life, in which neoplastic cells were found within the external granular layer, invading the perivascular spaces and internal granular layers.

The present report is based on the rarity of benign small low grade glioma having 17 years' postoperative follow up, no further focal convulsive crisis since surgical removal, and no use of antiepileptic drugs. occur in adults' stem are originated from

\section{CASE}

An 18-year old male patient reported a history of epileptic crisis on January $14^{\text {th }} 1991$, when started tonic-clonic movements in the right foot which rose to the homolateral side including the hemiface, and was followed by transient paralysis of this side. On the following day, the patient presented another crisis having the same clinical characteristics as the first. Brain computed tomography scan (CT) revealed a parasagital tumoral lesion in the superior frontal gyrus measuring $8 \mathrm{~mm} \times 5 \mathrm{~mm}$ (Figs 1 and 2). Cerebrospinal fluid (CSF) exam was negative for both neurocysticercosis and neuroschistosomiasis. It was prescribed to the patient Carbamazepine $200 \mathrm{mg}$ twice a day and instructed to return for follow up in 6 months. On August $30^{\text {th }} 1991$ the patient had 4 successive epileptic crisis with the same features as previously outlined. A repeat CT was performed on September $10^{\text {th }} 1991$ which revealed the same features as the first CT scan. Left frontoparietal craniotomy was performed on September $12^{\text {th }} 1991$ with total removal of the tumor, situated on a subcortical plane. Intraoperative identification of the tumor was extremely difficult due to its subcortical topography and small size (less than $10 \mathrm{~mm}$ ). The author used digital touch to locate the lesion because more accurate methods of identification were not available. The anatomopathological exam showed the presence of a low grade glioma. The follow-up exam

\section{PEQUENO GLIOMA DE BAIXO GRAU COM 17 ANOS DE SEGUIMENTO PÓS-OPERATÓRIO}

${ }^{1}$ Neurosurgical Unit of the Santa Isabel Hospital, João Pessoa PB, Brazil; ${ }^{2}$ Neurologist, Head of the Department of Movement Disorders of the Federal University of Paraíba; ${ }^{3}$ Neuroanesthesiologist; ${ }^{4}$ Radiologist, Head of the CEDRUL Radiological Clinic of Paraíba; ${ }^{5}$ Associated Physician. 


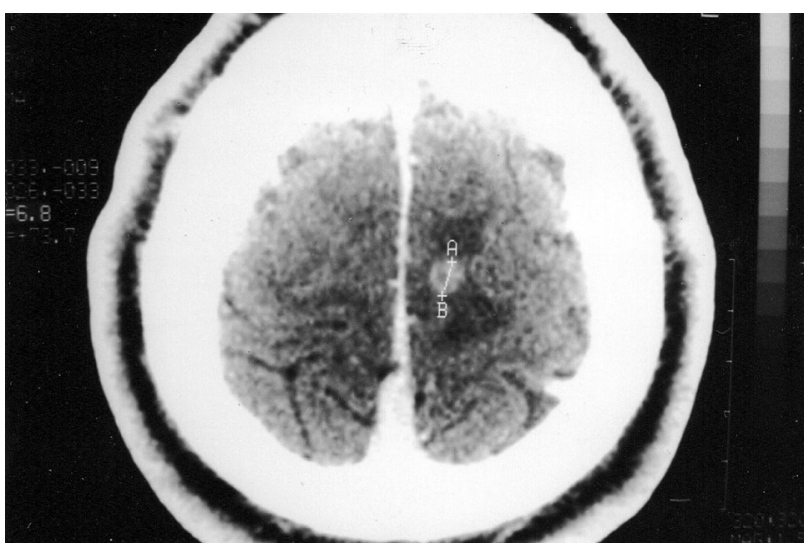

Fig 1. Brain CT scan showing the tumor measuring $8 \mathrm{~mm} \times 5 \mathrm{~mm}$.

was performed on June $10^{\text {th }} 2008$ and revealed normal neurological exam and no convulsive crisis and with no antiepileptic drugs were used throughout the follow up period. The latest cranial CT was performed on June $12^{\text {th }}$ 2008 and it did not show any evidence of tumor recurrence (Fig 3). The patient signed an inform consent for this publication.

\section{DISCUSSION}

The present study reports the results obtained of 17 years, after removal of a small low grade glioma measuring $8 \mathrm{~mm} \times 5 \mathrm{~mm}$ located in the left superior frontal gyrus.

There are few reports of glial small tumors without signs of intracranial expansion in the literature ${ }^{1,2}$. Cranial CT can appear normal in inspite of early glioma has grown in patients presenting transient neurological symptoms.

Some small glioma casuistics have been described. For instance, Nishio et al. ${ }^{1,2}$ reported 4 cases of astrocytic tumorette with the largest measuring $1,2 \mathrm{~cm}$, comprising 3 cases of low-grade astrocytoma and one of malignant astrocytoma. Nishio et al. $^{2}$ described 8 cases of small tumors, the largest measuring $15 \mathrm{~mm}$. The anatomopathological exam revealed the presence of 6 cases of low grade gliomas (fibrillar astrocytoma), and two anaplastic astrocytomas. From these 8 patients, 5 presented epileptic crisis only. Tamura et al. ${ }^{3}$ described also 8 cases of small gliomas, 6 of them were benign and two malignant. Tumors were located in separate gyrus and measured less than $20 \mathrm{~mm}$.

Glioblastomas which develop in the cerebral cortex or in the subcortical area, trigger more precocious epileptic crisis than gliomas found in deeper layers of the brain. Focal epileptic crisis can often outpoint the beginnings of a glioma ${ }^{1-3,6}$, as demonstrated in this study.

The early stages of development of gliomas in the central nervous system have already been clearly described.

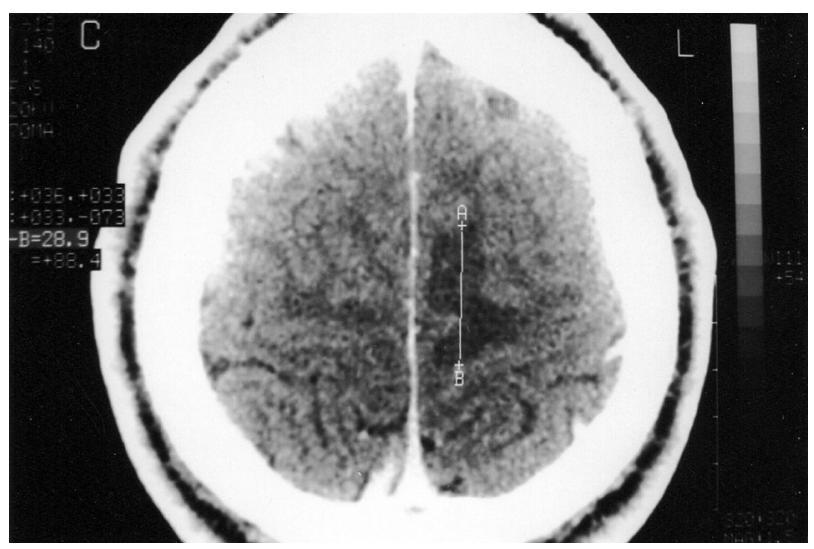

Fig 2. Area of cortical edema caused by the lesion.

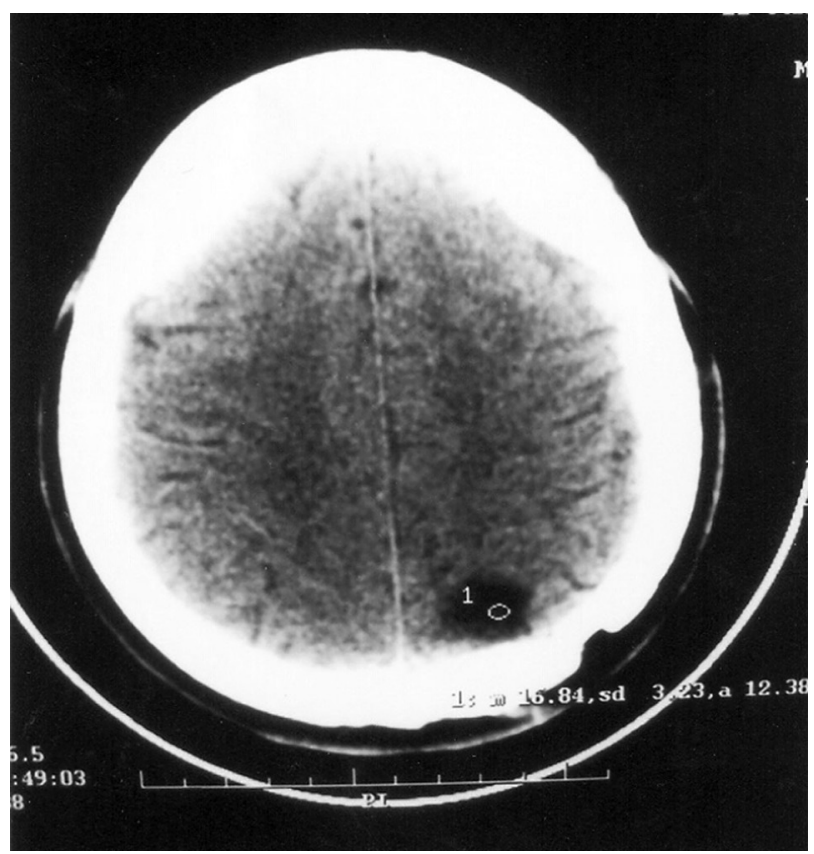

Fig 3. Brain CT showed no recurrence of the lesion.

Graeber et al. ${ }^{7}$ believe that potential proliferation of microglia in cerebral gliomas may be induced by tumor growth, or by the microglia gave rise to a glioma. Kornblith $^{8}$ stated that several growth factor peptides have influence in self-perpetuation of gliomas.

In regard to small human gliomas, Engel et al. ${ }^{6}$ described small neoplastic lesions in the temporal lobe, composed of well-differentiated oligodendrongliomas and Schwann cells. In all four cases reported by Nishio et al. ${ }^{1}$, all glioma foci observed in surgical specimens were composed of neoplastic astrocytic cells.

In terms of surgical treatment, the majority of the authors propose early surgery, thereby achieving a high cure rate in benign gliomas s,5,6,10 $^{2,}$

This case presented had early diagnosis of microtu- 
mor and subsequent surgical treatment which resulted in cure of both the tumor lesion and the epilepsy caused by this tumor.

\section{REFERENCES}

1. Nishio S, Takai Y, Baaky RAE. Astrocystic tumorette: microscopic to minute foci of glioma unexpectedly found in autopsy or surgical specimens. J. Neurosurg Sci 1987;31:201-206.

2. Nishio S, Morioka T, Takeshita I, Fukui M. Glial tumourettes (glial microtumours): their clinical and histopathological manifestations. Acta Neurochir (Wien) 1996;138:818-823.

3. Tamura M, Shibasaki T, Horikoshi S, Ono N, et al. Small gliomas: metabolism and blood flow. Neurol Med Chir (Tokyo) 1994;34:91-94.

4. Rubinstein LJ, Sarcomas. Definition, cytogenesis and classification. In Ru- binstein $L J(E d)$. Tumors of the central nervous system. Washington, Armed Forces Institute of Pathology 1972:190-191

5. Amacher AL, Torres QU, Rittenhouse S. Congenital medulloblastoma: an inquiry into origins. Case report. Child's Nerv Syst 1986;2:262-265.

6. Engel Jr. J, Brown WJ, Kuhl DE, Phelps ME, Mazziorra JC, Crandall PH. Pathological findings underlying focal temporal lobe hypometabolism in partial epilepsy. Ann Neurol 1982;12:518-528.

7. Graeber MB, Scheithauer BW, Kreutzberg GW. Microglia in brain tumors. Glia 2002;40:252-259.

8. Kornblith PL. Perpetual motion and glioma growth. Surg Neurol 1997;47: 282-283.

9. Laws Jr. ER, Taylor WF, Clifton MB, Okazaki H. Neurosurgical management of low-grade astrocytoma of the cerebral hemispheres. J Neurosurg 1984; 61:665-673.

10. Recht LD, Lew R, Smith TW. Suspected low-grade glioma: is deferring treatment safe? Ann Neurol 1992:31:431-436. 